\title{
Transformer Wireless Monitoring System Using Arduino/XBEE
}

\author{
Amevi Acakpovi ${ }^{1}$, Chiedozie Odazie ${ }^{2}$, Issah Babatunde Majeed $^{3}$, George Eduful ${ }^{4}$, \\ Nana Yaw Asabere ${ }^{5}$ \\ ${ }^{1}$ Department of Electrical and Electronics Engineering, Faculty of Engineering, Accra Technical University, Accra, Ghana \\ ${ }^{2}$ Department of Electrical and Electronics Engineering, Accra Institute of Technology, Accra, Ghana \\ ${ }^{3}$ Department of Electrical and Electronics Engineering, Faculty of Engineering, Takoradi Technical University, Sekondi-Takoradi, Ghana \\ ${ }^{4}$ Electricity Company of Ghana, Accra, Ghana \\ ${ }^{5}$ Department of Computer Science, Faculty of Applied Sciences, Accra Technical University, Accra, Ghana
}

Email address:

acakpovia@gmail.com (A. Acakpovi), light.odazie@yahoo.com (C. Odazie), issahmajeed@gmail.com (I. B. Majeed), georgeeduful@yahoo.com (G. Eduful), yawasabere2011@gmail.com (N. Y. Asabere)

\section{To cite this article:}

Amevi Acakpovi, Chiedozie Odazie, Issah Babatunde Majeed, George Eduful, Nana Yaw Asabere. Transformer Wireless Monitoring System Using Arduino/XBEE. American Journal of Electrical Power and Energy Systems. Vol. 8, No. 1, 2019, pp. 1-10.

doi: $10.11648 /$ j.epes. 20190801.11

Received: November 28, 2018; Accepted: December 21, 2018; Published: January 31, 2019

\begin{abstract}
Distribution transformers are generally provided with advanced control measures that ensure their operation and safety at a high reliability because their failure usually leads to long power outage, increase maintenance cost and unreliable provision of electricity to customers. Despite the protection measures that accompany a distribution transformer, there is still a need to provide extra remote monitoring systems to increase the reliability of operation and the confidence of instantaneous fault reporting. This paper deals with the design and construction of automatic monitoring system for power transformer parameters. An Arduino board coupled with XBEE module were programmed to enable the monitoring of voltage, current and temperature on a typical power transformer. The system was implemented and tested successfully. Results showed that the voltage versus temperature as well as current versus voltage characteristic obtained, were closed to datasheet specifications and therefore confirming the reliability of the proposed design. This system is therefore recommended as an additional protection that should be added to Power Transformers.
\end{abstract}

Keywords: Transformer, Arduino Board, XBEE Module, Wireless Monitoring, Transformer Fault Reporting

\section{Introduction}

Wireless monitoring systems have been in existence for a long time and they are mainly used in industry to monitor key performance parameters from remote locations. In many industries, there are critical information that needs to be monitored for effective production and not all these parameters can be physically monitored. Remote monitoring becomes fundamental in situations where accessibility to the parameters to be monitored is not obvious or in situations where this poses great safety risks. Similar situations are common in Oil and Gas industry where operators are located far apart from the oil field that presents numerous hazards. Ideally, sensors are placed in the field to provide real time information on essential parameters like temperature, pressure etc. In many other industries, weight, height, volume, pressure level among others are monitored parameters needed to achieve reliable and efficient operation.

In the power industry, remote monitoring and protection of power transformers has been an area of great interest. Power transformers are vital to the operation of substations and also for the safe distribution of electricity. In Ghana, power transformers adopted by the national electricity distribution company (Electricity Company of Ghana, ECG) have varying rates and specifications in terms of protection systems but are mostly oil type. Their specific role in substations is to step-down transmission voltages to distribution voltages to serve appropriate loads $[1,2]$. Power 
transformers are equipped with some minimum protection that ensures their safety and reliable operation. It is imperative that power transformers' breakdown is minimized to the extreme because their occurrence may lead to power outages and severe economic drawbacks etc.

Causes of transformer failures may be attributed to several factors which include overheating, voltage and current fluctuations and overload [3-6]. An early detection of an excess voltage or current may be useful in disconnecting the transformer or redirecting some loads to other transformers especially in situation where those mechanisms are not automatically installed. This situation is a true reflection of many transformers' installation in the past 10 years which were not equipped with automatic means of disconnection. Furthermore, information on the temperature of oil, pressure of gases emanating from the chemical decomposition of the oil as a result of shorts or overheating can be detected at the incipient level using remote monitoring systems. This assertion is confirmed by [3] who attempted a similar monitoring of transformer operation by using data acquisition methods that have evolved today in programming microcontrollers. Rafa, Mahmod, Mariun, Hassan, \& Mailah (2002) equally attempted a similar study by using microcontroller but were also limited with means of fault information transmission.

In practice, transformer protection is achieved through buchholz relay protection, earth-fault and overcurrent relay protection [8]. The buchholz relay appears in the form of a dome vessel, usually mounted on the pipe connecting the main tank and the conservator and it uses a mechanism that detects the presence of gases in the oil both at the initial and high levels respectively. The Earth-faults relays on the other hand provide protection against earth-faults only while the overcurrent relays provide protection mainly against phaseto-phase faults and overloading.

Alternative protection of transformer include the design of three phase differential relay [9] which improves upon the quick determination of harmonics. Dashti \& Sanaye-Pasand (2014) developed a new adaptive approach to improve the performance of power transformer differential relay that was found to be faster and smarter than the simple differential relay approach. Differential relay protection is more appropriate to generator than transformer because of the many synchronizers needed for frequency, phase and magnitude of the voltage monitored at both side of the transformer and also for the sizing of the relevant current transformers. The proposed adaptive technique in this study, differentiates between internal faults and other faults relating to the differential current trajectory.

Despite all the existing protection systems listed above, an additional remote monitoring of the transformer oil parameters including temperature, level and pressure can serve as a measure of reliability to effectively check the operation of the transformer, should any of the previous protection measures fail. Additionally, the transformer voltage and current level can also be monitored remotely using a wireless medium to spontaneously alert the operators in the control room of an earth fault or phase to phase short circuit.

As a solution to the remote monitoring of transformer protection, Supervisory Control and Data Acquisition Systems (SCADA) have been mostly used in the power systems industry. It is a centralized system that uses a number of sensors, communication media and protocol to bring remote information to a central point where some controls can also be directly executed like shutting-down of a device remotely, disconnection of a transformer or turning-on other appliances [11, 12]. SCADA systems however suffer some deficiencies which are cost, network reliability and more importantly security of data transfer in the system [13]. Communication media which mostly are wired type, must be reliable for effective communications. Also, the cost of SCADA system is comparatively higher than many other means of communication.

Today, XBEE modules present a reliable means of wireless communication systems that uses radio wave within some limited distances. XBEE modules have already been used to achieve good energy monitoring [14] as well as temperature monitoring [15]. The module has been equally used in medicine to perform remote monitoring of patient heart rate and blood pressure [16, 17].

Coupled with Arduino processing board, they have become the solution for remote control of processes at a relatively lesser cost with increeased reliability [18]. In this paper, a simple model of Arduino board coupled to an XBEE module is designed, simulated and constructed to achieve remote monitoring of transformer parameters.

The rest of the paper is structured as follow. Section 2 deals with the material and method followed by the result and discussion sections as well as the conclusion and recommendation.

\section{Methodology}

The proposed wireless monitoring system is derived from a set of different components selected in the field of electrical and electronics engineering. This system provides a real time monitoring of temperature, current, voltage and vibration of the transformer to enable the utility provider pinpoint problems on the transformer and the grid and proactively attend to them to minimize unplanned outages. The component of the proposed system consists of a microcontroller, an XBEE module, a temperature sensor, a current sensor, and a voltage sensor. The components are grouped into the following units: sensing unit, processing unit, transmitter unit and receiver unit.

\subsection{Sensing Unit}

The Sensing Unit comprises of the temperature sensor, current sensor and the voltage sensor. The transformer voltage is detected using a voltage divider circuit. Additionally, a hall-effect current sensor, ACS712 is used to detect the current in the circuit and a TMP36 sensor is used to sense the temperature of the transformer. 


\subsubsection{Temperature Sensor}

The temperature sensor used to measure the temperature of the transformer oil is the TMP36. This particular sensor has three pins; a positive, a ground, and a signal as illustrated in Figure 1. This is a linear temperature sensor. A change in temperature of one degree centigrade is equal to a change of 10 millivolts at the sensor output. The TMP36 sensor has a nominal $750 \mathrm{mV}$ at $25^{\circ} \mathrm{C}$ about room temperature.

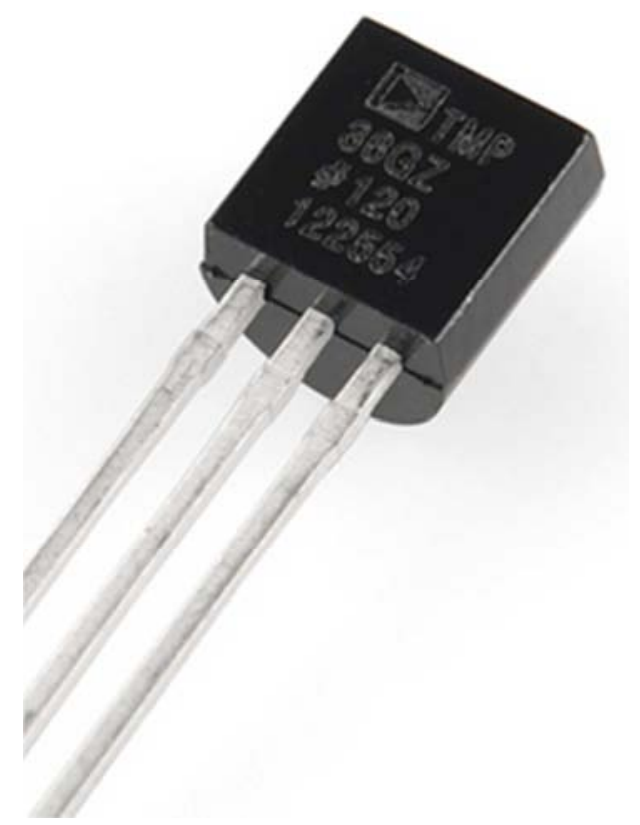

Figure 1. Temperature sensor TMP36.

The TMP36 do not require any external calibration to provide typical accuracies of $\pm 1^{\circ} \mathrm{C}$ at $25^{\circ} \mathrm{C}$ and $\pm 2{ }^{\circ} \mathrm{C}$ over the range, $-40^{\circ} \mathrm{C}$ to $+125^{\circ} \mathrm{C}$. The sensor is connected as follows. The first pin of the sensor is connected to $5 \mathrm{~V}$, the second to the ADC of the microcontroller and the third to ground as shown below.

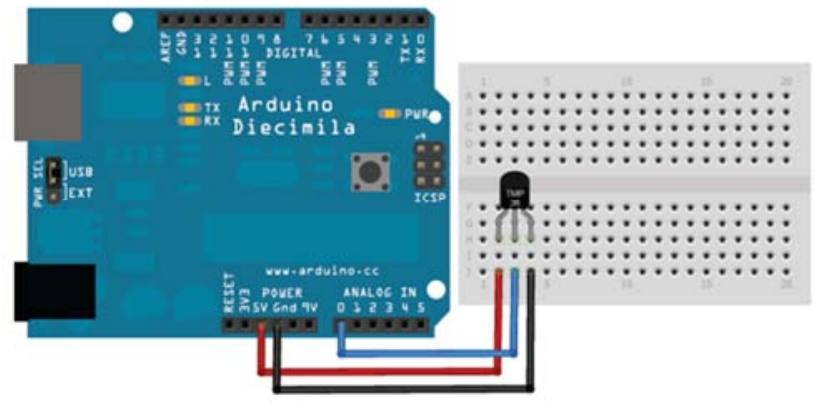

Figure 2. Interfacing TMP36 to microcontroller.

The temperature sensor is installed at the transmitter side of the system. The analog signal from the sensor is converted to a digital signal by the microcontroller at the transmitter side. The microcontroller then sends the digital signal serially to the XBEE module for onward wireless transmission.

\subsubsection{Current Sensor}

Protection of power transformers against excess current is crucial. This is why a current sensor is installed to measure in real time the current originally sensed by a current transformer. The current sensor used is ACS712. The sensor gives the precise current measurement for both $\mathrm{AC}$ and $\mathrm{DC}$ signals. Thick copper conductor and signal traces allows for survival of the device up to 5 times overcurrent conditions. The ACS712 sensor gives an analog voltage signal output that varies linearly with the sensed current. The device requires $5 \mathrm{VDC}$ for VCC and a couple of filter capacitors.

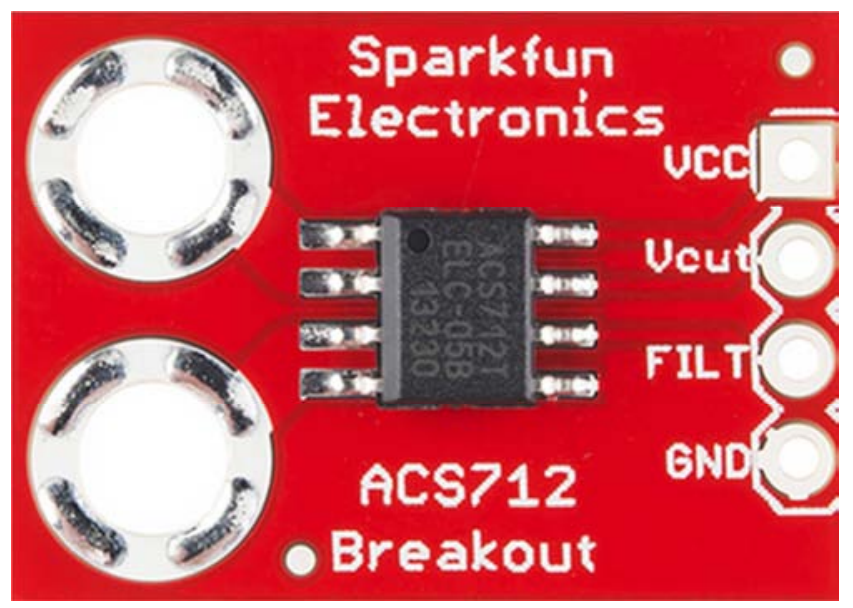

Figure 3. Current sensor (ACS712).

\subsection{Processing Unit}

At the heart of the processing unit is the ATMEGA328P microcontroller. It receives the real-time analog data from the sensors through its Analog to Digital Converter (ADC). The digital equivalent of the analog data is then processed by the microcontroller based on control algorithms programmed and stored in its flash memory. The control algorithm is written such that the real temperature, voltage and current values can be obtained from the sensors output signals.

\subsection{Transmitter Unit}

The transmitter unit comprises of the sensing unit, the microcontroller and the XBEE module. The processed information from the microcontroller is wirelessly transmitted so it can be viewed remotely. At the heart of the wireless transmission is the Series 1 XBEE $1 \mathrm{~mW}$ transceiver.

The Series XBEE $1 \mathrm{~mW}$ transceiver is a $2.4 \mathrm{GHz}$ Zigbee technology. The module uses the 802.15 .4 command set for serial communication. These modules allow for a very reliable and simple communication between microcontrollers, computers and any system with a serial port. Point to point and multi-point networks are also supported.

\subsubsection{Atmega328p Microcontroller}

Aside the digital and the analog pins, there are other pin that play very important role in the operation of the microcontroller. Two (2) of such pins are used to provide oscillation to the microcontroller. This is to provide a clock pulse that is needed for synchronization so that communication can occur in synchronism between the 
microcontroller and the device connected to it. The Atmega328P is a low-power chip hence it only needs between $1.8-5.5 \mathrm{~V}$ of power to operate.

The Atmega328P datasheet, as illustrated in Figure 4, has an internal analog-to-digital converter (ADC). With this, the chip is able to interpret analog inputs and interact with the physical world. The ADC has three (3) functional pins which are AVCC, AREF and GND. AVCC is for power supply. The ADC needs its own power supply in order to work. GND is for ground. AREF is the reference voltage that the ADC uses to convert an analog signal to its corresponding digital value.

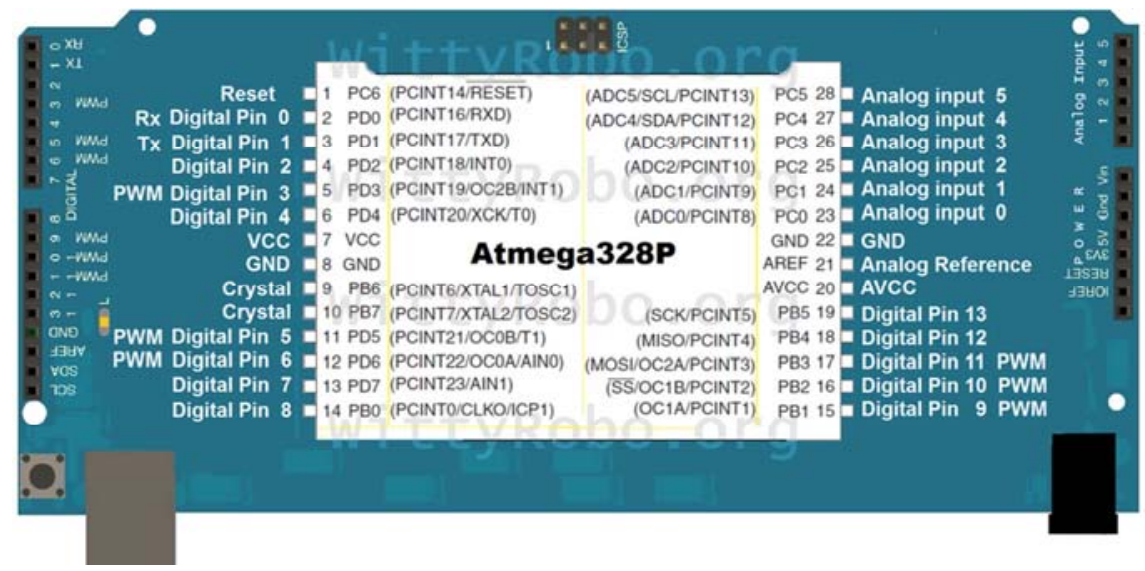

Figure 4. Atmega328P Pin-Out.

\subsubsection{XBEE Module}

The XBEE module forms a very crucial part of the system design. The module helps to exchange information wirelessly from the transmission side of the system to the receiving side. They communicate using IEEE 802.15, a standard which specifies the physical layer and media access control for lowrate wireless personal area networks. The XBEE module makes it possible for the microcontroller to communicate wirelessly using Zigbee technology. It was interfaced with the microcontroller through a serial connection for transmitting and receiving signals. Two (2) XBEE modules are used in this system. One at the transmitter unit and another at the receiver unit. The XBEE modules are usually configured with default settings (network settings and destination addresses). The XBEE module is interfaced to the microcontroller as shown in Figure 5.

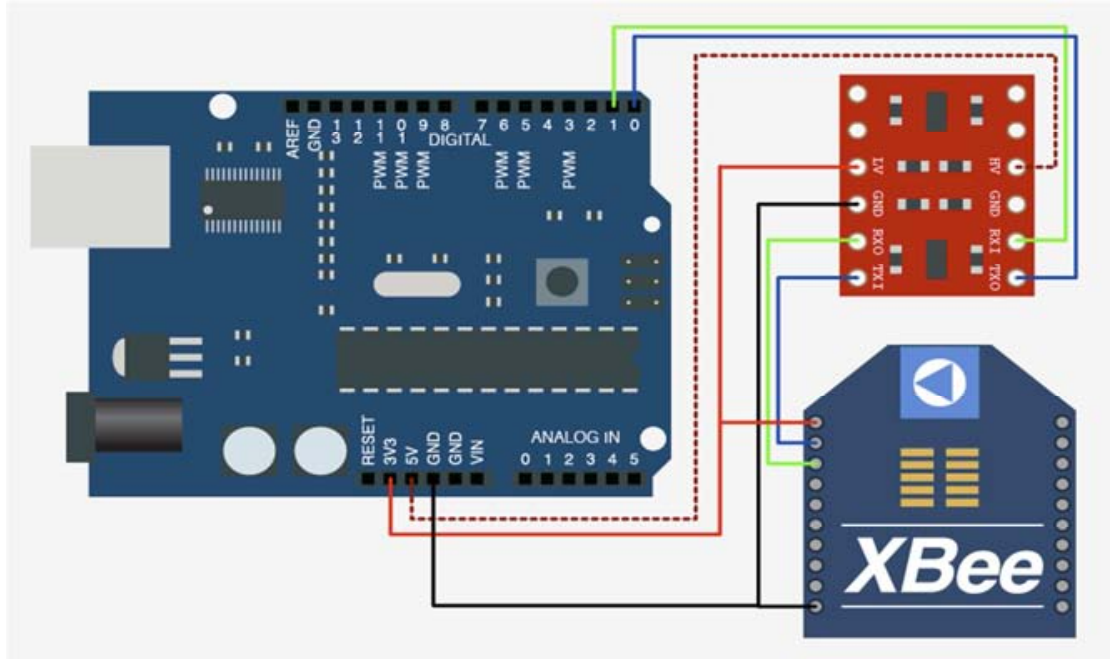

Figure 5. Interfacing XBEE to the microcontroller.

The XBEE modules operate at a voltage of 3.3 volts. Subsequently, sending a $5 \mathrm{~V}$ serial command to them from the microcontroller will destroy them. This is why a logic level converter was used as an intermediary between the microcontroller and the XBEE module. The logic converter converts the $5 \mathrm{~V}$ from the controller to $3.3 \mathrm{~V}$ and also converts the $3.3 \mathrm{~V}$ from the XBEE module to $5 \mathrm{~V}$. This allows for a bi- directional logic communication between the two devices with different operating voltages. It can be observed from Figure 5 that the logic level converter is powered by both $5 \mathrm{v}$ and $3.3 \mathrm{v}$ supplies. The XBEE module needs 4 connections to operate: power, ground, $R_{X}$ and $T_{X}$ as shown in the Figure 5. Figure 6 also shows the transmitter circuit. 


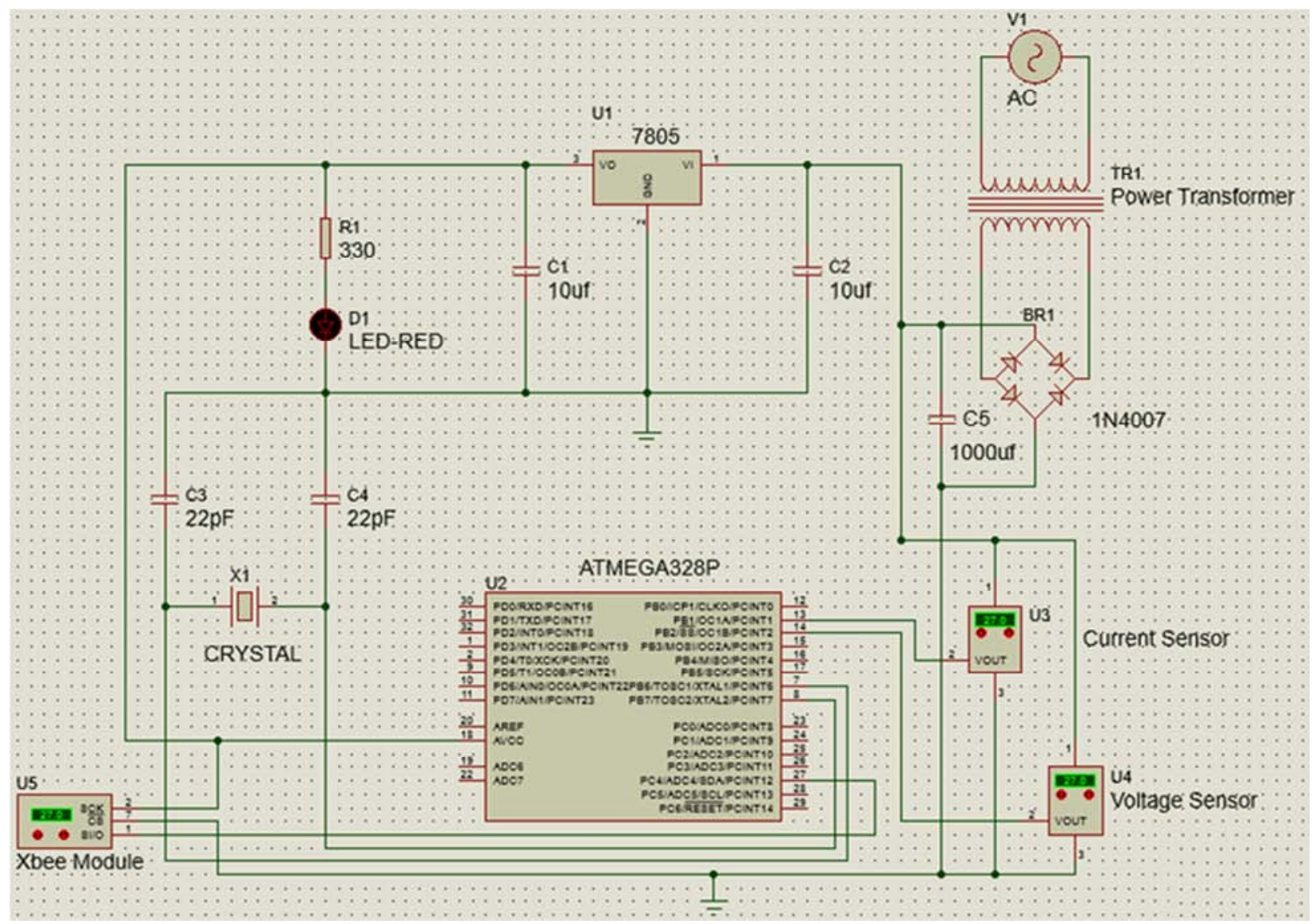

Figure 6. Transmitter circuit.

\subsection{Receiver Unit}

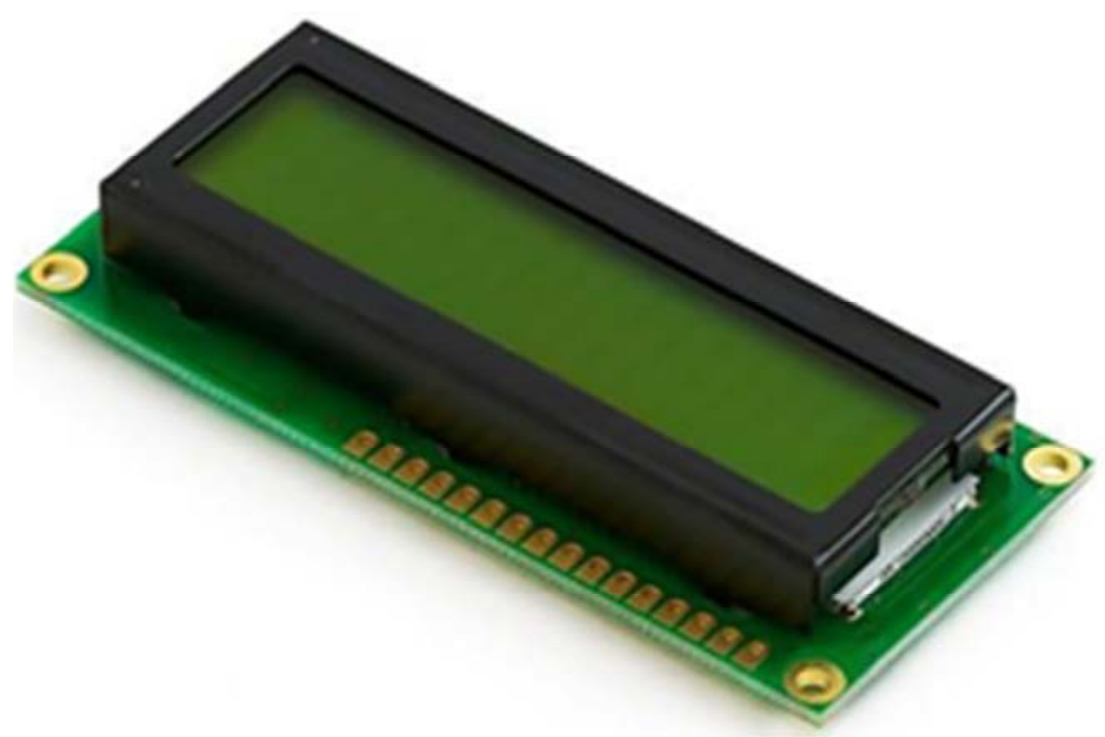

Figure 7. $L C D$ screen.

The receiver unit is made up of the ATMEGA328P microcontroller, the XBEE module and the Liquid crystal display (LCD) screen as shown in Figure 7. As the microcontroller receive signals from the XBEE module, the information read from the sensors is displayed on the LCD. The LCD used is a character display. The character display controller used by the LCD module is a Hitachi HD44780, which uses a relatively simple interface between the microcontroller and the LCD.

The interface to the LCD is a parallel bus, which allows easy interfacing to the microcontroller. Figure 8 shows the receiver circuit. 


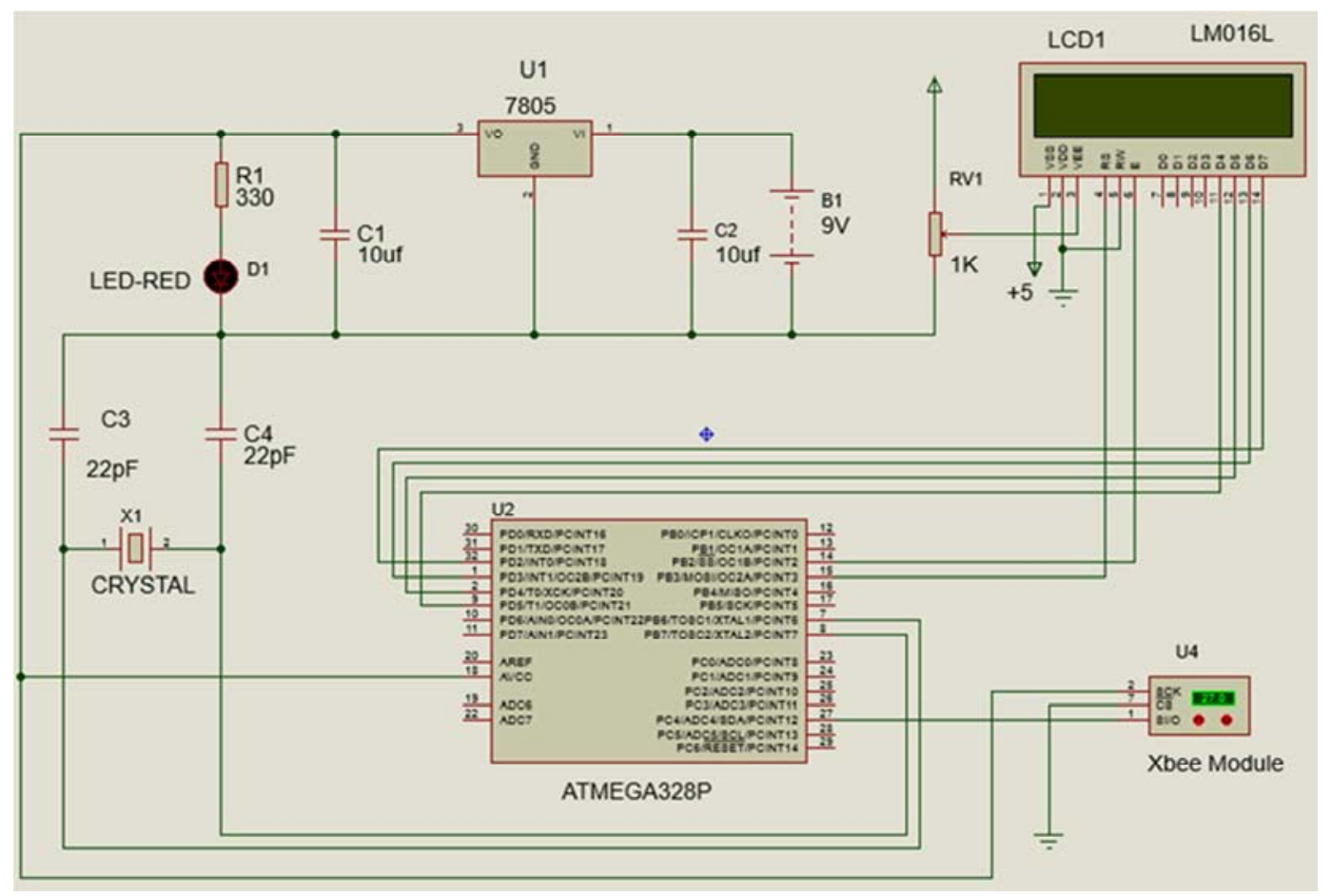

Figure 8. Receiver circuit.

\subsection{Assembly of the Transformer's Wireless Monitoring System}

This section illustrates the connection of the individual parts leading to the finally constructed and packaged device. Figure 9 shows the assembled transmitter circuit

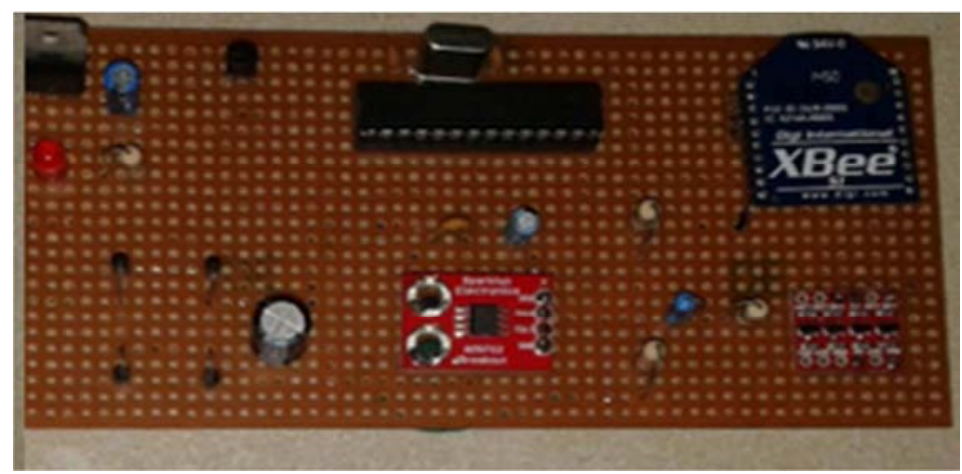

Figure 9. Assembled transmitter circuit.

Figure 10 shows the assembled receiver circuit.

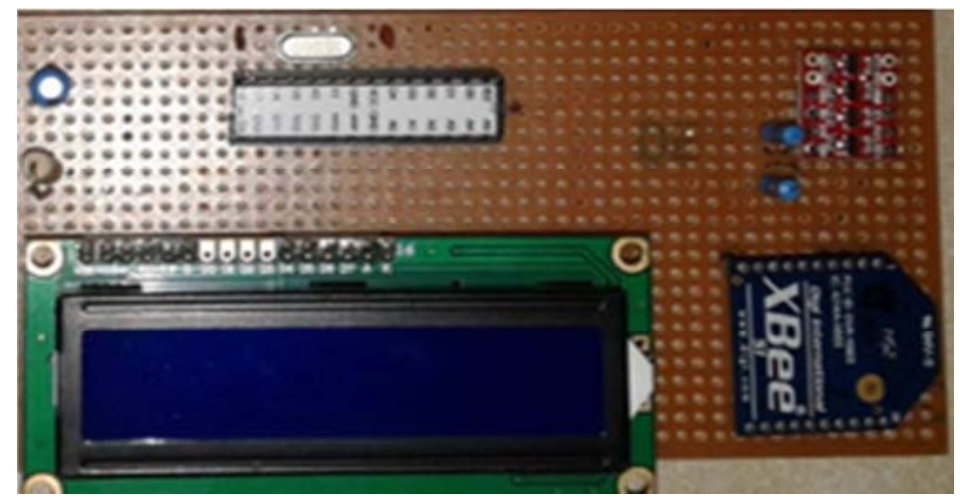

Figure 10. Assembled receiver circuit. 


\subsection{Program Development}

This section depicts the process of developing the software. Flowcharts have been used to show the details of the main program leading the wireless monitoring of the transformer system.

The flowchart in Figure 11 illustrates the logic and sequential flow behind the software program that run in the transmitter unit. When the system is turned on, the microcontroller at the transmitter unit system reads and process signals from the temperature, current and voltage sensors of the sensing unit and then sends this information to the XBEE module to be relayed wirelessly.

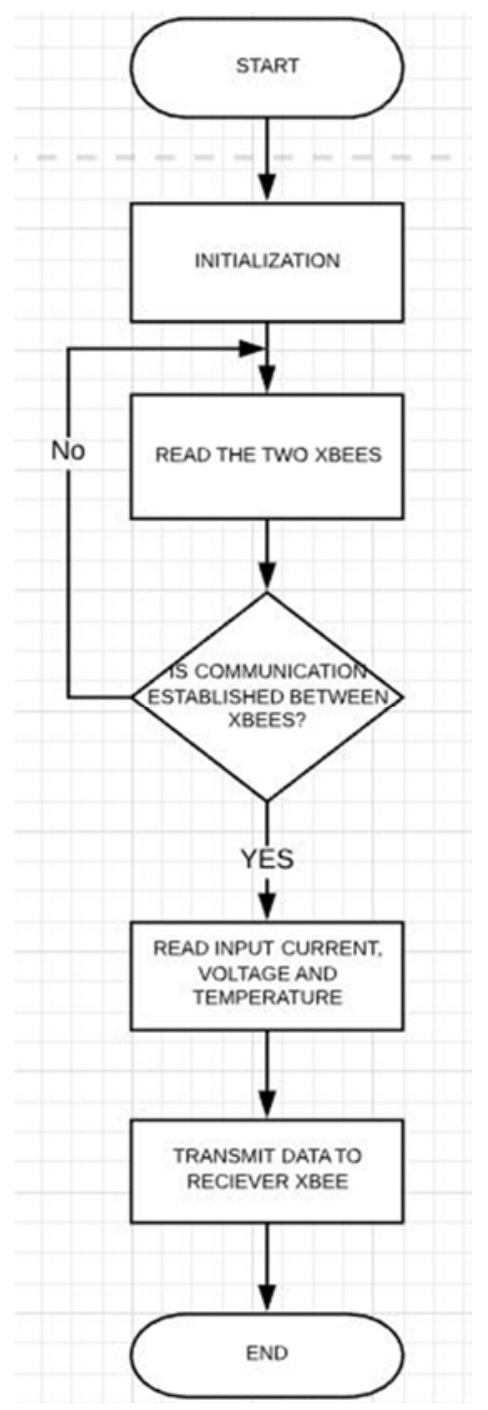

Figure 11. Transmitter flowchart. receiver unit. After the information has been relayed wirelessly from the transmitter unit, the same information is received by the XBEE at the receiver unit and sent to the microcontroller.

The microcontroller then segregates the data appropriately using synchronizing characters sent from the transmitter. These characters are ' $\mathrm{T}$ ' for temperature, ' $\mathrm{I}$ ' for current and ' $\mathrm{V}$ ' for voltage. With the help of these characters, the microcontroller is able to differentiate between the data relating to the physical quantities mentioned above. The microcontroller then processes the data for the various quantities and displays the results on the LCD screen.

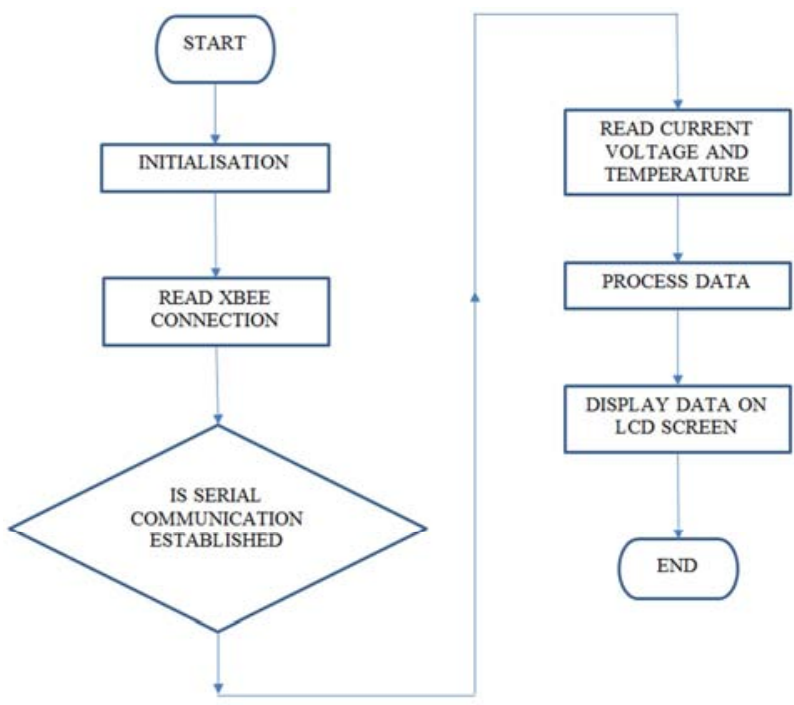

Figure 12. Receiver flowchart.

\section{Results and Discussions}

The results are discussed and interpreted in this section. During the testing, the output voltage and current of a transformer from the oil transformer's wireless monitoring system were collected every thirty minutes in a day from 7:00 AM till the next day 06:30 AM.

Table 1 shows the data on voltage, current and oil temperature, received from oil transformer's wireless monitoring system and the normal data displayed by the manual monitoring system installed in the substation for the duration of the experiment. For the experiment, a $150 \mathrm{kVA}$, three-phase transformer with a line-voltage ratio of $400 \mathrm{~V} / 11$ $\mathrm{kV}$ which was connected in star-delta, was used. The associated current transformer has a current ratio of 500/5 on the low voltage side and protective transformers on the $440 \mathrm{~V}$ side have a current ratio of $500 / 5$.

The flowchart in Figure 12 illustrates the logic and sequential flow behind the software program that run in the

Table 1. Data collected from conducted experiments.

\begin{tabular}{lllllll}
\hline \multirow{2}{*}{ TIME } & Manual Data & \multicolumn{5}{l}{ XBEE System data } \\
\cline { 2 - 7 } & $\mathbf{V}_{\mathbf{1}}[\mathbf{V}]$ & $\mathbf{I}_{\mathbf{1}}[\mathbf{A}]$ & $\left.\mathbf{T}_{\mathbf{1}}{ }^{\circ} \mathbf{C}\right]$ & $\mathbf{V}_{\mathbf{2}}[\mathbf{V}]$ & $\mathbf{I}_{\mathbf{2}}[\mathbf{A}]$ & $\mathbf{T}_{2}\left[{ }^{\circ} \mathbf{C}\right]$ \\
\hline 07:00 AM & 412 & 220 & 49 & 400 & 207 & 48 \\
$07: 30 \mathrm{AM}$ & 389 & 85 & 40 & 406 & 114 & 38 \\
\hline
\end{tabular}




\begin{tabular}{|c|c|c|c|c|c|c|}
\hline \multirow{2}{*}{ TIME } & \multicolumn{3}{|c|}{ Manual Data } & \multicolumn{3}{|c|}{ XBEE System data } \\
\hline & $V_{1}[\mathbf{V}]$ & $\mathbf{I}_{1}[\mathbf{A}]$ & $\mathbf{T}_{1}\left[{ }^{\circ} \mathrm{C}\right]$ & $\mathbf{V}_{2}[\mathbf{V}]$ & $\mathbf{I}_{2}[\mathbf{A}]$ & $\mathbf{T}_{2}\left[^{\circ} \mathbf{C}\right]$ \\
\hline 08:00 AM & 415 & 243 & 51 & 402 & 233 & 50 \\
\hline 08:30 AM & 391 & 220 & 49 & 427 & 245 & 49 \\
\hline 09:00 AM & 424 & 210 & 49 & 427 & 219 & 53 \\
\hline 09:30 AM & 384 & 208 & 48 & 428 & 183 & 52 \\
\hline 10:00 AM & 414 & 94 & 40 & 413 & 86 & 38 \\
\hline $10: 30 \mathrm{AM}$ & 425 & 101 & 41 & 403 & 75 & 39 \\
\hline 11:00 AM & 415 & 243 & 51 & 408 & 264 & 52 \\
\hline $11: 30 \mathrm{AM}$ & 409 & 211 & 49 & 411 & 232 & 52 \\
\hline 12:00 PM & 392 & 228 & 50 & 428 & 256 & 54 \\
\hline 12:30 PM & 425 & 165 & 45 & 393 & 186 & 42 \\
\hline 01:00 PM & 400 & 293 & 54 & 422 & 311 & 51 \\
\hline 01:30 PM & 426 & 92 & 40 & 384 & 92 & 43 \\
\hline 02:00 PM & 387 & 187 & 47 & 413 & 167 & 43 \\
\hline 02:30 PM & 427 & 114 & 42 & 403 & 110 & 45 \\
\hline 03:00 PM & 385 & 165 & 45 & 398 & 184 & 47 \\
\hline 03:30 PM & 405 & 217 & 49 & 419 & 213 & 50 \\
\hline 04:00 PM & 426 & 117 & 42 & 422 & 104 & 42 \\
\hline 04:30 PM & 402 & 196 & 48 & 417 & 201 & 44 \\
\hline 05:00 PM & 418 & 271 & 53 & 386 & 285 & 51 \\
\hline 05:30 PM & 409 & 246 & 51 & 400 & 226 & 49 \\
\hline 06:00 PM & 389 & 200 & 48 & 400 & 206 & 45 \\
\hline 06:30 PM & 390 & 278 & 53 & 382 & 305 & 51 \\
\hline 07:00 PM & 413 & 163 & 45 & 428 & 159 & 43 \\
\hline 07:30 PM & 427 & 203 & 48 & 386 & 220 & 46 \\
\hline 08:00 PM & 395 & 211 & 49 & 412 & 200 & 49 \\
\hline 08:30 PM & 420 & 239 & 51 & 400 & 269 & 54 \\
\hline 09:00 PM & 388 & 263 & 52 & 390 & 266 & 56 \\
\hline 09:30 PM & 389 & 154 & 45 & 386 & 175 & 43 \\
\hline 10:00 PM & 424 & 88 & 40 & 397 & 79 & 42 \\
\hline 10:30 PM & 408 & 280 & 53 & 408 & 309 & 52 \\
\hline 11:00 PM & 403 & 117 & 42 & 401 & 140 & 44 \\
\hline 11:30 PM & 425 & 127 & 43 & 404 & 128 & 39 \\
\hline $12: 00 \mathrm{AM}$ & 425 & 265 & 52 & 412 & 265 & 56 \\
\hline $12: 30 \mathrm{AM}$ & 421 & 163 & 45 & 422 & 136 & 47 \\
\hline 01:00 AM & 390 & 228 & 50 & 406 & 254 & 47 \\
\hline 01:30 AM & 396 & 197 & 48 & 415 & 177 & 48 \\
\hline 02:00 AM & 419 & 265 & 52 & 426 & 252 & 52 \\
\hline 02:30 AM & 406 & 204 & 48 & 391 & 220 & 52 \\
\hline 03:00 AM & 386 & 192 & 47 & 411 & 180 & 48 \\
\hline 03:30 AM & 399 & 158 & 45 & 413 & 156 & 47 \\
\hline 04:00 AM & 430 & 284 & 54 & 384 & 287 & 50 \\
\hline 04:30 AM & 398 & 116 & 42 & 428 & 103 & 38 \\
\hline 05:00 AM & 386 & 193 & 47 & 395 & 210 & 46 \\
\hline 05:30 AM & 395 & 249 & 51 & 382 & 253 & 52 \\
\hline 06:00 AM & 382 & 205 & 48 & 421 & 209 & 50 \\
\hline 06:30 AM & 403 & 126 & 43 & 384 & 146 & 46 \\
\hline
\end{tabular}

Figures 13,14 and 15 show respectively, the relationship between the voltage, current and temperature for the manual and the XBEE system. Furthermore, a cost analysis is depicted in Table 2, showing that the device was built at a relatively lower cost.

Table 2. Cost of designed oil transformer's wireless monitoring systems.

\begin{tabular}{|c|c|c|c|c|}
\hline $\mathbf{S} / \mathbf{N}$ & Item & Quantity & Unit & Cost [\$] \\
\hline 1 & Xbee Module & 2 & 12.45 & 35 \\
\hline 2 & Voltage sensor & 1 & 10.20 & 15 \\
\hline 3 & Temperature sensor & 1 & 13.11 & 20 \\
\hline 4 & Microcontroller & 1 & 9.17 & 15 \\
\hline 5 & LCD & 1 & 10.48 & 17 \\
\hline 6 & Passive components & 1 & 7.86 & 10 \\
\hline 7 & Current sensor & 1 & 6.55 & 10 \\
\hline 9 & Labor Cost & 1 & & 33 \\
\hline \multicolumn{2}{|c|}{ TOTAL } & & & 150 \\
\hline
\end{tabular}

The same Figures 13, 14 and 15 demonstrate a consistent correlation between the data obtained manually and the data 
transmitted through the XBEE system therefore confirming the effectiveness of the design.

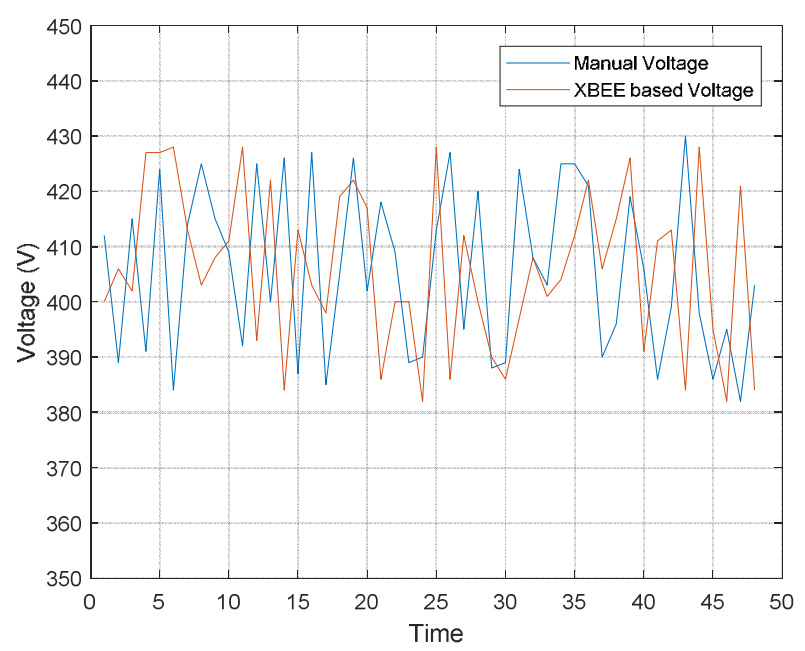

Figure 13. Voltages recorded for both manual and XBEE systems.

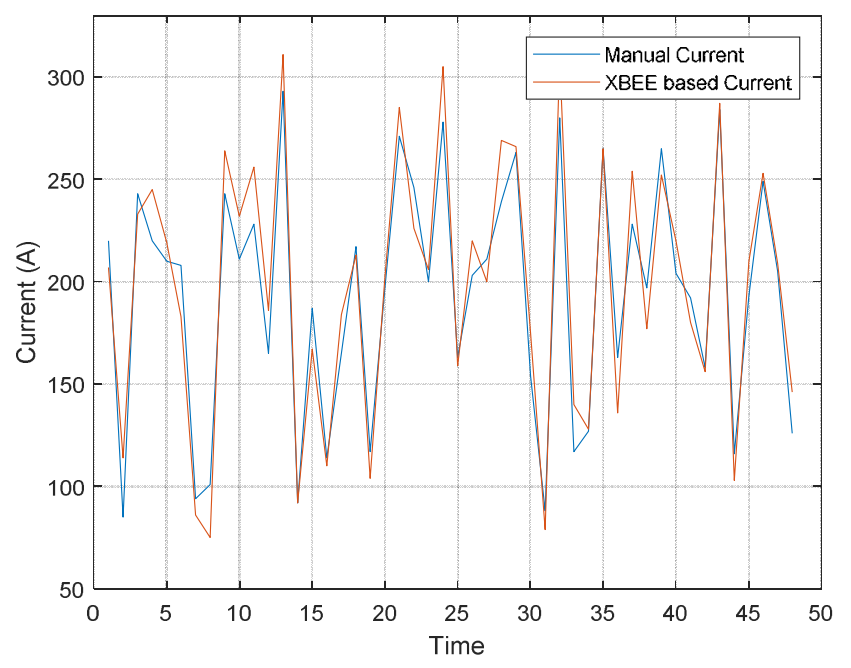

Figure 14. Current recorded for both manual and XBEE systems.

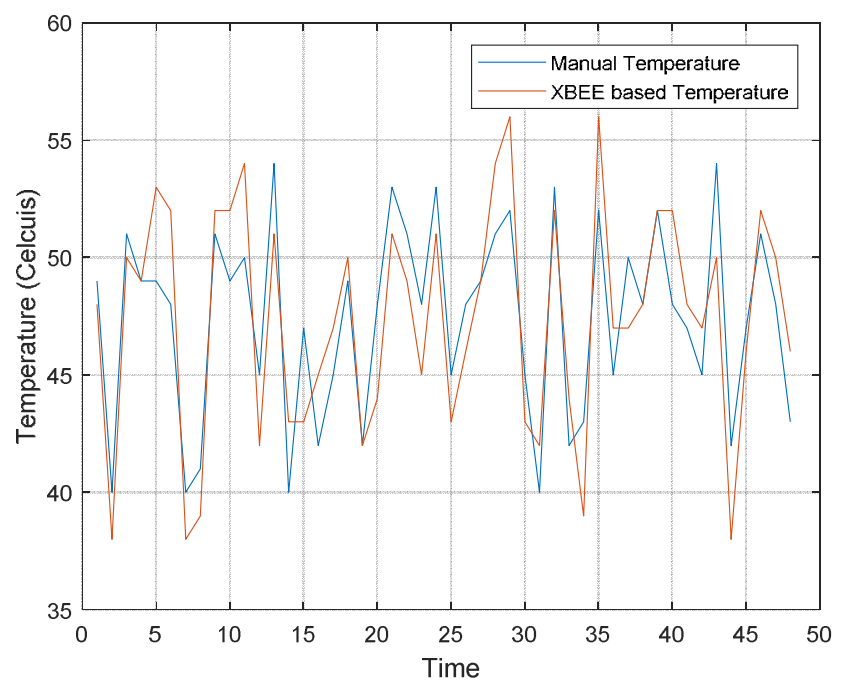

Figure 15. Temperature recorded for both manual and XBEE systems.

\section{Conclusions}

In summary, this paper presented the design and the construction of a microcontroller-based system capable of monitoring voltage, current and temperature of a distribution transformer and transmit data wirelessly. The developed product makes use of XBEE modules to transfer data from one point to another. This method helps the maintenance officers to have a real time information on the health of the transformers without having to be physically present on the field. Upon detection of any abnormality, one can take action immediately to prevent any disastrous failure of the transformers. In a distribution network, there are many distribution transformers and associating each transformer with such system, can improve upon the speed of fault detection and therefore reduce transformer downtime. The time delay for data transfer between the transmitter and the receiver is lesser than a second. This makes the system very reliable and efficient. With modern technology it is possible to monitor a large number of parameters of distributed transformer at a relatively high cost. The challenge is to balance the functions of the monitoring system with its cost and reliability.

\section{References}

[1] M. Arshad, S. M. Islam, and A. Khaliq, "Power transformer asset management," Power Syst. Technol. 2004. PowerCon 2004. 2004 Int. Conf., vol. 2, no. November, p. 1395-1398 Vol.2, 2004.

[2] Abb-Group, “Transformer Handbook,” Quality, p. 213, 2004.

[3] D. Arvind, S. Khushdeep, K. Deepak, and Nanak, "Condition monitoring of power transformer: a review," in 2008 IEEE/PES Transmission and Distribution Conference and Exposition, 2008, pp. 2-7.

[4] T. Suwanasri, E. Chaidee, and C. Adsoongnoen, "Failure statistics and power transformer condition evaluation by dissolved gas analysis technique," in Proceedings of 2008 International Conference on Condition Monitoring and Diagnosis, CMD 2008, 2007, pp. 492-496.

[5] R. Murugan and R. Ramasamy, "Failure analysis of power transformer for effective maintenance planning lectric utilities," Eng. Fail. Anal., vol. 55, pp. 182-192, 2015.

[6] A. C. Nishant, "Failure Analysis of a Power Transformer Using Dissolved Gas Analysis - a Case Study," Int. J. Res. Eng. Technol., vol. 3, no. 5, pp. 300-303, 2014.

[7] A. Rafa, S. Mahmod, N. Mariun, W. Z. W. Hassan, and N. F. Mailah, "Protection of power transformer using microcontrollerbased relay," Student Conf. Res. Dev., pp. 224-227, 2002.

[8] D. M. Mehta, P. Kundu, A. Chowdhury, and V. K. Lakhiani, "DGA diagnostics save transformers - Case studies," in 2015 International Conference on Condition Assessment Techniques in Electrical Systems, CATCON 2015 Proceedings, 2016, pp. 116-120.

[9] C. H. Einvall and J. R. Linders, "A Three-phase Differential Relay for Transformer Protection," IEEE Trans. Power Appar. Syst., vol. 94, no. 6, pp. 1971-1980, 1975. 
[10] H. Dashti and M. Sanaye-Pasand, "Power transformer protection using a multiregion adaptive differential relay," IEEE Trans. Power Deliv., vol. 29, no. 2, pp. 777-785, 2014.

[11] National Communications System, "Supervisory Control and Data Acquisition (SCADA) Systems," Tech. Inf. Bull. 04-1, no. October, p. 76, 2004.

[12] D. Peharda, I. Ivanković, and N. Jaman, "Using Data from SCADA for Centralized Transformer Monitoring Applications,” in Procedia Engineering, 2017, vol. 202, pp. 65-75.

[13] V. M. Igure, S. A. Laughter, and R. D. Williams, "Security issues in SCADA networks," Comput. Secur., vol. 25, no. 7, pp. 498-506, 2006.

[14] X. Liu, H. Chen, M. Wang, and S. Chen, "An XBee-Pro based energy monitoring system," Telecommun. Networks Appl. Conf. (ATNAC), 2012 Australas., pp. 1-6, 2012.
[15] V. Boonsawat, "XBee wireless sensor networks for temperature monitoring," Second Conf. ..., p. 6, 2010.

[16] N. S. A. Zulkifli, F. K. Che Harun, and N. S. Azahar, "XBee wireless sensor networks for Heart Rate Monitoring in sport training," in 2012 International Conference on Biomedical Engineering, ICoBE 2012, 2012, pp. 441-444.

[17] T. H. Y. Ling, L. J. Wong, J. E. H. Tan, and C. K. Lee, "XBee Wireless Blood Pressure Monitoring System with Microsoft Visual Studio Computer Interfacing," in Proceedings International Conference on Intelligent Systems, Modelling and Simulation, ISMS, 2015, vol. 2015-Octob, pp. 5-9.

[18] A. H. Kioumars and L. Tang, "ATmega and XBee-based wireless sensing," in ICARA 2011 - Proceedings of the 5th International Conference on Automation, Robotics and Applications, 2011, pp. 351-356. 